\title{
Satisfaction of Patients and Physicians with Treatments for Rheumatoid Arthritis: A Population-Based Survey in China
}

This article was published in the following Dove Press journal: Patient Preference and Adherence

\author{
Nan Jiang, (iD) ',* Pingting Yang, 2,* \\ Shengyun Liu, ${ }^{3} *$ Hongbin $\mathrm{Li}^{4}$ \\ Lijun Wu, ${ }^{5}$ Xiaofei Shi, ${ }^{6}$ \\ Yongfei Fang, (D) ${ }^{7}$ Yi Zhao, $^{8}$ \\ Jian $\mathrm{Xu}^{9}{ }^{9}$ Zhenyu Jiang, (iD ${ }^{10}$
} Zhenbiao Wu, "' Xinwang Duan, ${ }^{12}$ Qian Wang, (D)' Xinping Tian,' Mengtao Li,' Xiaofeng Zeng'

'Department of Rheumatology, Peking Union Medical College Hospital, Peking Union Medical College and Chinese Academy of Medical Sciences, Key Laboratory of Rheumatology and Clinical Immunology, Ministry of Education, Beijing, People's Republic of China; ${ }^{2}$ Department of Rheumatology and Immunology, First Affiliated Hospital, China Medical University, Shenyang, People's Republic of China; ${ }^{3}$ Department of Rheumatology, The First Affiliated Hospital of Zhengzhou University,

Zhengzhou, People's Republic of China; ${ }^{4}$ Department of Rheumatology, Affiliated Hospital of Inner Mongolia Medical College, Hohhot, Inner Mongolia, People's Republic of China; ${ }^{5}$ Department of Rheumatology and Immunology, People's Hospital of Xinjiang Uygur Autonomous Region, Urumqi, Xinjiang Uygur Autonomous Region, People's Republic of China; ${ }^{6}$ Department of Rheumatology and Immunology, The First Affiliated Hospital, and College of Clinical Medicine of Henan University of Science and Technology, Luoyang, Henan, People's Republic of China; ${ }^{7}$ Department of Rheumatology, Southwest Hospital, Third Military Medical University, Chongqing, People's Republic of China; ${ }^{8}$ Department of Rheumatology and Immunology, West China Hospital, Sichuan University, Chengdu, People's Republic of China; ${ }^{9}$ Department of Rheumatology and Immunology, First Affiliated Hospital of Kunming Medical University, Kunming, Yunnan, People's Republic of China; ${ }^{10}$ Department of Rheumatology, The First Hospital of jilin University, Changchun, Jilin, People's Republic of China; "Department of Clinical Immunology and Rheumatology, Xijing Hospital Affiliated to the Fourth Military Medical University, Shanxi, People's Republic of China; ${ }^{12}$ Department of Rheumatology, The Second Affiliated Hospital of Nanchang University, Nanchang, Jiangxi, People's Republic of China

*These authors contributed equally to this work

Correspondence: Xiaofeng Zeng; Mengtao L Department of Rheumatology, Peking Union Medical College Hospital, No. I Shuaifuyuan, Wangfujing Ave, Beijing 100730, People's Republic of China

$\mathrm{Tel} / \mathrm{Fax}+86-10-69158793$

Email zengxfpumc@।63.com; mengtao.li@cstar.org.cn
Purpose: Rheumatoid arthritis (RA) is a systemic inflammatory disease characterized by chronic destructive synovitis and possible multisystem involvement. This study aimed to survey the treatment satisfaction of physicians and patients with RA, and to explore the potential factors.

Patients and Methods: This cross-sectional study was conducted in 12 centers across China between March 2018 and April 2018. The Treatment Satisfaction Questionnaire for Medication version II was used to assess the treatment satisfaction of patients and physicians. Multivariable regression analysis was used to determine the factors independently associated with treatment satisfaction of patients.

Results: The patients' satisfaction ( $\mathrm{n}=335)$ with biological disease-modifying antirheumatic drugs (bDMARDs) was higher than physicians' satisfaction $(n=146)$ regarding the side effects (95.0 \pm 14.3 vs $84.6 \pm 15.7, \mathrm{P}<0.001)$ and convenience $(74.6 \pm 21.2$ vs $69.1 \pm 16.5, \mathrm{P}=0.002)$. Among physicians, global satisfaction with bDMARDs was higher than that with conventional synthetic DMARDs (csDMARDs). The multivariable regression analysis showed that age was positively associated with satisfaction of patients, while college or above education and selfassessment of disease severity were inversely associated with satisfaction. Treatment satisfaction was associated positively with the quality of communication with the physician and inversely with treatment costs

Conclusion: For bDMARDs, the treatment satisfaction of patients with RA is generally higher than that of physicians'. Physicians' satisfaction with bDMARDs is higher than with csDMARDs. Age, education, disease severity, communication with the physician, and treatment costs are independently associated with the treatment satisfaction among patients. Physician-patient communication should be improved in clinical practice. Treatment costs should be taken into account when physicians make decisions.

Keywords: patient, physician, rheumatoid arthritis, treatment satisfaction, TSQM-II

\section{Introduction}

Rheumatoid arthritis (RA) is a systemic inflammatory disease characterized by chronic destructive synovitis and possible multisystem involvement. ${ }^{1-3}$ The prognosis of patients with RA has improved dramatically in the last two decades with a better understanding of the pathogenesis, the validation of reliable assessment tools, and novel medication development. Current strategies recommend early referral, early diagnosis, and early initiation of effective therapy to achieve the treatment goal. This treat-to-target management prevents the progression of joint 
damage and optimizes physical function, work capability, social participation, and quality of life.,

Despite the marked advances in RA treatments, improved disease remission rate fails to meet patient's need for health care and support fully. In fact, the adverse reactions, methods of administration, long-term treatment duration, and adherence require attention. ${ }^{6,7}$ In addition, patients and their physicians may have different perceptions of the success of therapy. Non-adherence to treatment has serious impacts on patient outcomes. Patients' satisfaction with treatment significantly affects the decisions regarding the treatment of $\mathrm{RA}^{8-10}$ as well as with adherence to treatment. ${ }^{11,12}$

The Treatment Satisfaction Questionnaire for Medication, version II (TSQM-II), is a useful tool to survey the treatment satisfaction of physicians and patients. ${ }^{13}$ The TSQM has been validated in heterogeneous populations. ${ }^{13,14}$ The TSQM has been used in patients with rheumatic diseases. ${ }^{15-17}$ This questionnaire has been shown to have high internal consistency. ${ }^{18}$

The Chinese Registry of Rheumatoid Arthritis (CREDIT) is the first nationwide, multicenter, prospective registry of patients with RA in China, which was established in November 2016. It reported baseline characteristics, point prevalence of remission and treatment regimens with both conventional synthetic diseasemodifying antirheumatic drugs (csDMARDs) and biological DMARDs (bDMARDs), and prevalence of major comorbidities (cardiovascular disease, fragility fracture and cancer) in Chinese RA patients. Up to May 2017, point prevalence of remission was $14.9 \%, 4.2 \%, 4.3 \%$, and $4.3 \%$ according to disease activity score- 28 joints using C-reactive protein (DAS28-CRP), clinical disease activity index (CDAI), simplified disease activity index (SDAI), and the 2011 American College of Rheumatology (ACR)/European League Against Rheumatism (EULAR) remission criteria in 8701 patients, respectively. ${ }^{19}$ Up to August 2017, the prevalence rates of cardiovascular disease, fragility fracture and cancer were $2.2 \%, 1.7 \%$ and $0.6 \%$ in 13,210 patients, respectively. ${ }^{20}$ Nevertheless, the characteristics and the related factors of treatment satisfaction are poorly known in Chinese patients with RA and their physicians. Therefore, this study aimed to investigate the treatment satisfaction of patients and physicians and also to explore the underlying related factors. The results might provide insights and evidence for improving patient satisfaction and shared decision management in clinical practice.

\section{Materials and Methods}

\section{Study Design and Population}

This cross-sectional study of patients with RA and their physicians was conducted between March 31, 2018, and April 30, 2018, in 12 centers from 11 provinces in China. These 11 provinces covered eastern, western, northern, and southern China. The details of each center are shown in Supplementary Table 1. At each center, physicians and patients who were the participants of CREDIT registry were invited to the survey. Eligible patients were aged $\geq 18$ years and had been diagnosed with RA for $>6$ months, according to the 2010 ACR/EULAR classification criteria. ${ }^{21}$ Patients were excluded if they had not received RA treatment previously or had comprehension barriers to reading Chinese. All the physicians included in the study were rheumatologists. This study was approved by the research ethics committee of Peking Union Medical College Hospital, which was accepted by all participating centers as the central institutional review board. All participants signed an informed consent form. This study was registered with ClinicalTrials.gov (\#NCT03483597).

\section{Questionnaires}

The patient questionnaire collected information on sociodemographic characteristics, duration of RA, self-assessed disease severity, current medication, communication with physicians, treatment cost for RA, and satisfaction towards general diagnostic and treatment services. The physician questionnaire collected information on working years, number of outpatient visits per day, consultation time for each patient, and the proportion of shared decisionmaking. The TSQM-II was used to assess the treatment satisfaction of patients and physicians. ${ }^{13}$ This TSQM-II questionnaire includes 11 questions covering four domains of treatment satisfaction: treatment effectiveness, side effects, convenience of administration, and global satisfaction. The score in each domain ranges from 0 (extremely dissatisfied) to 100 (extremely satisfied). For patients, TSQM-II was used to assess the treatment satisfaction for all medications they ever received and for bDMARDs. For physicians, TSQM-II was used to assess the treatment satisfaction for csDMARDs and bDMARDs. To simplify the questionnaire, targeted synthetic DMARDs (tsDMARDs) were included in bDMARDs. The TSQM-II was translated by professional translators into Chinese. Physicians in each center were invited to proofread the Chinese and English versions of the physicians' and 
patients' questionnaires. Last, physicians finalized the questionnaires and agreed to use them in this study. Only the Chinese versions were used in the study. The TSQM-II has been previously used in China. ${ }^{22}$

The scores were calculated as in the original paper by Atkinson et al. ${ }^{13}$ Effectiveness: ([(Item $1+$ Item 2) - 2] divided by 12) $\times 100$. Side effects: ([Sum of Item 4 to Item 6 ) -3 ] divided by 12 ) $\times 100$. If one item is missing: ([(Sum of the two completed items) -2$]$ divided by 8$) \times 100$. Convenience: ([Sum of Item 7 to Item 9) - 3] divided by 18) $\times 100$. If one item is missing: ([(Sum of the two completed items) -2$]$ divided by 12) $\times 100$. Global satisfaction: ([Sum of Item 10 to Item 11) -2 ] divided by 12$) \times 100$

\section{Data Collection}

The outpatients were surveyed during a routine treatment follow-up visit to their hospital. The survey was anonymous and used online questionnaires. The Disease Activity Score 28 (DAS28) and the physician's global assessment were collected by the physicians. The outpatients filled out the patients' questionnaires (Appendixes 1 and 2) at the department of rheumatology after signing the informed consent form. An interview was required for RA patients who had limited eyesight or were elderly. The physician participants filled out the physicians' questionnaires (Appendixes 3 and $\underline{4}$ ) during their spare time. Effective questionnaire was defined as a completely filledout questionnaire. Patients with incompletely filled-out questionnaires were excluded from the analysis.

\section{Statistical Analysis}

SPSS 20.0 (IBM, NY, USA) was used for statistical analysis. The continuous variables were tested for normal distribution using the Kolmogorov-Smirnov test. The mean \pm standard deviation (SD) (normal distribution) and median (range) (skewed distribution) were calculated for continuous variables. The Mann-Whitney $U$-test (skewed distribution) and the Student's $t$-test (normal distribution) were used for analysis. Categorical variables are presented as frequency (percentage) and were analyzed using the chi-square test. The univariable linear regression analyses were performed for baseline characteristics of the patients to identify factors associated with the global satisfaction of patients $(P<0.05)$. Then, the significant variables were entered into a multivariable linear regression. The linear regressions were performed using the standardized TSQMII total scores. $P$ values $<0.05$ were considered statistically significant.

\section{Results}

\section{Characteristics of the Study Population}

A total of 1365 patients and 164 physicians were invited and filled out the questionnaires. The questionnaire retrieval rates for patients and physicians were both $100 \%$. After verification, questionnaires from 1237 patients and 146 physicians were qualified for analysis (Figure 1). The effective questionnaire rates for patients and physicians were $90.6 \%$ and $89.0 \%$, respectively. The baseline characteristics of patients are shown in Table 1. The patients were $48.9 \pm 13.4$ years of age, and $82.5 \%$ were female. Regarding selfassessment of disease severity, 3.2\% reported extremely mild, $34.4 \%$ reported mild, $43.9 \%$ reported moderate, and $18.6 \%$ reported severe. Two-thirds of the patients $(66.1 \%)$ reported full communication with their physicians. Cost of treatment represented $<10 \%$ of the household income for $35.7 \%$ of the patients, $10-30 \%$ for $22.2 \%, 31-50 \%$ for $21.3 \%$, and $>50 \%$ for $20.8 \%$.

Among 1037 (83.8\%) patients with RA who were on csDMARDs at the time of survey, $749(72.2 \%)$ were using methotrexate, 428 (40.3\%) were using leflunomide, 108 $(10.4 \%)$ were using sulfasalazine, 372 (35.9\%) were using hydroxychloroquine, 158 (15.2\%) were using tripterygium. Among 202 (16.3\%) patients with RA who were on bDMARDs at the time of survey, 37 (18.3\%) were using infliximab, 14 (6.9\%) were using adalimumab, 10 (5.0\%) were using etanercept, 119 (58.9\%) were using generic drugs of etanercept, 28 (13.9\%) were using tocilizumab, 14 (6.9\%) were using tofacitinib.

The baseline characteristics of physicians are shown in Supplementary Table 2: $39.7 \%$ of whom had $>10$ years of work experience, followed by $32.9 \%$ with $6-10$ years of work experience, $21.2 \%$ with $2-5$ years, and $6.2 \%$ with $<2$ years. Nearly half of the physicians $(46.6 \%)$ reported

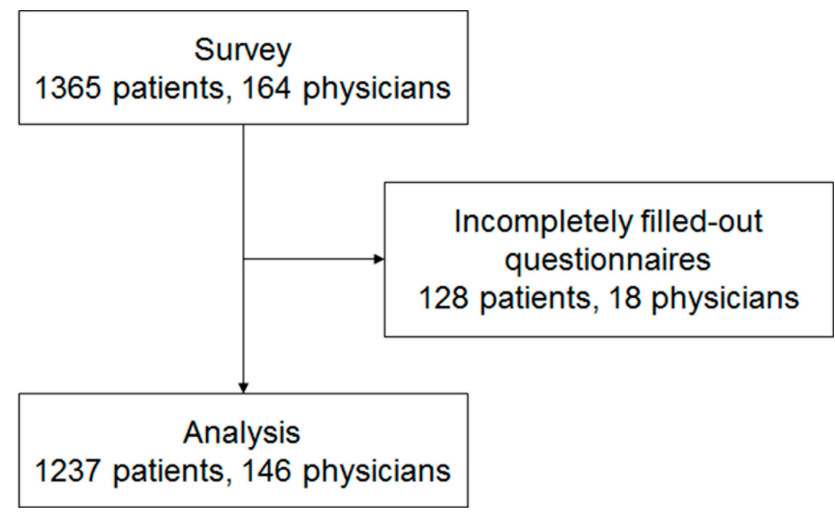

Figure I Patient flowchart. 
Table I Characteristics of the Patients

\begin{tabular}{|c|c|}
\hline Characteristics & $N=1237$ \\
\hline Age (years) & $48.9 \pm 13.4$ \\
\hline $\begin{array}{l}\text { Sex } \\
\qquad \text { Male } \\
\text { Female }\end{array}$ & $\begin{array}{l}217(17.5 \%) \\
1020(82.5 \%)\end{array}$ \\
\hline $\begin{array}{l}\text { Occupation } \\
\text { Persons in charge of party organizations, state } \\
\text { organizations, mass organizations, social } \\
\text { organizations, enterprises, and institutions } \\
\text { Professionals } \\
\text { Clerks } \\
\text { Service staff } \\
\text { Agricultural, forestry, animal husbandry, fisheries, } \\
\text { and auxiliary personnel } \\
\text { Manufacturing and related personnel } \\
\text { Soldier } \\
\text { Others }\end{array}$ & $\begin{array}{l}109(8.8 \%) \\
85(6.9 \%) \\
148(12.0 \%) \\
183(14.8 \%) \\
39(3.2 \%) \\
I(0.1 \%) \\
548(44.3 \%)\end{array}$ \\
\hline $\begin{array}{l}\text { Education Level } \\
\text { Junior high school or below } \\
\text { Senior high school } \\
\text { College } \\
\text { Master degree or above }\end{array}$ & $\begin{array}{l}555(44.9 \%) \\
342(27.6 \%) \\
312(25.2 \%) \\
28(2.3 \%)\end{array}$ \\
\hline $\begin{array}{l}\text { Duration of Rheumatoid Arthritis (Years) } \\
\begin{array}{l}<2 \\
2-5 \\
6-10 \\
>10\end{array}\end{array}$ & $\begin{array}{l}385(31.1 \%) \\
358(28.9 \%) \\
218(17.6 \%) \\
276(22.3 \%)\end{array}$ \\
\hline $\begin{array}{l}\text { Severity of the Disease Assessed by the Patient } \\
\text { Severe } \\
\text { Moderate } \\
\text { Mild } \\
\text { Extremely mild } \\
\text { DAS28-ESR } \\
\text { DAS28-CRP } \\
\text { PtGA }\end{array}$ & $\begin{array}{l}230(18.6 \%) \\
543(43.9 \%) \\
425(34.4 \%) \\
39(3.2 \%) \\
4.2 \pm 1.7 \\
3.7 \pm 1.6 \\
4.29 \pm 2.52\end{array}$ \\
\hline $\begin{array}{l}\text { Current Medication } \\
\text { csDMARDs } \\
\text { Glucocorticoids } \\
\text { bDMARDs }\end{array}$ & $\begin{array}{l}1037(83.8 \%) \\
488(39.5 \%) \\
202(16.3 \%)\end{array}$ \\
\hline $\begin{array}{l}\text { Communication with Physicians } \\
\text { Full communication } \\
\text { Good communication, but a little hasty } \\
\text { Average communication level and can get the } \\
\text { information } \\
\text { Less communication with physicians } \\
\text { Basically no communication }\end{array}$ & $\begin{array}{l}818(66.1 \%) \\
247(20.0 \%) \\
98(7.9 \%) \\
60(4.9 \%) \\
14(1.1 \%)\end{array}$ \\
\hline
\end{tabular}

(Continued)
Table I (Continued).

\begin{tabular}{|l|l|}
\hline Characteristics & $\mathbf{N}=1237$ \\
\hline Cost of Treatment for Rheumatoid Arthritis, & \\
Proportion of Household Income (\%) & \\
$<10$ & $442(35.7 \%)$ \\
$10-30$ & $274(22.2 \%)$ \\
$31-50$ & $264(21.3 \%)$ \\
$>50$ & $257(20.8 \%)$ \\
\hline Satisfaction Towards General Diagnostic and & \\
Treatment Services & \\
Extremely satisfied & $745(60.2 \%)$ \\
Very satisfied & $287(23.2 \%)$ \\
Satisfied & $109(8.8 \%)$ \\
Somewhat satisfied & $79(6.4 \%)$ \\
Not quite satisfied & $6(0.5 \%)$ \\
Dissatisfied & $3(0.2 \%)$ \\
Extremely dissatisfied & $8(0.7 \%)$ \\
\hline
\end{tabular}

Note: Data are expressed as mean \pm standard deviation or $n(\%)$.

Abbreviations: bDMARDs, biological disease-modifying antirheumatic drugs; csDMARDS, conventional synthetic disease-modifying antirheumatic drugs; DAS28ESR, disease activity score 28-erythrocyte sedimentation rate; DAS28-CRP, disease activity score 28-C-reactive protein; PtGA, patient global assessment of disease activity.

10-20 outpatient visits per day. Most of the physicians (59.6\%) communicated with patients for 5-10 mins. Regarding the proportion of shared decision-making, $5.5 \%$ reported $<10 \%, 30.8 \%$ reported $10-30 \%, 29.5 \%$ reported $31-50 \%$, and $34.2 \%$ reported $>50 \%$.

\section{Scores of Satisfaction}

The TSQM-II summary scores are shown in Table 2; the difference in satisfaction between physicians and patients is also shown. A total of 335 patients were previously treated with bDMARDs or currently using bDMARDs. For bDMARDs, patients' satisfaction $(\mathrm{n}=335)$ was higher than physicians' satisfaction $(\mathrm{n}=146)$ regarding side effects (median, 100 vs $87.5, P<0.001$ ) and convenience (median, 75 vs $68.8, P=0.001)$. The physicians' satisfaction data for csDMARDs are provided in Table 2. For physicians, the effectiveness and global satisfaction were higher for bDMARDs than for csDMARDs $(P<0.05)$.

The radar charts with the nine items of satisfaction are shown in Figures 2 and 3. The areas of the radar charts for the satisfaction with bDMARDs were 1.93 and 1.72 for patients and physicians, respectively. In question (Q) 3, Q4, Q5, Q7, and Q8, the satisfaction levels of the patients 
Table 2 TSQM-II Summary Scores

\begin{tabular}{|l|l|l|l|l|}
\hline Treatment & & Patients & Physicians & P \\
\hline All medications (patients' questionnaire)/csDMARDs (physicians' & $\mathrm{N}$ & 1237 & 146 \\
questionnaire) $^{\text {a }}$ & Median (range) & $83.3(0-100)$ & $66.7(33.3-100)$ \\
Effectiveness & Median (range) & $100(16.7-100)$ & $75(16.7-100)$ \\
Side effects & Median (range) & $81.3(18.6-100)$ & $68.8(31.3-100)$ \\
Convenience & Median (range) & $83.3(8.3-100)$ & $66.7(16.7-100)$ \\
Global satisfaction & N & 335 & 146 & $75(33.3-100)^{*}$ \\
bDMARDs & Median (range) & $83.3(0-100)$ & 0.302 \\
Effectiveness & Median (range) & $100(8.3-100)$ & $87.5(16.7-100)^{*}$ & $<0.001$ \\
Side effects & Median (range) & $75(0-100)$ & $68.8(12.5-100)$ & 0.001 \\
Convenience & Median (range) & $75(0-100)$ & $75(16.7-100)^{*}$ & 0.889 \\
Global satisfaction & (100) \\
\hline
\end{tabular}

Notes: 'Satisfaction with all medications or bDMARDs was assessed in the patients' questionnaire, while satisfaction with csDMARDs or bDMARDs was assessed in the physicians' questionnaire. $* P<0.05$, bDMARDs vs csDMARDs in physicians.

Abbreviations: bDMARDs, biological disease-modifying antirheumatic drugs; csDMARDs, conventional synthetic disease-modifying antirheumatic drugs; SD, standard deviation.

were higher than those of the physicians $(P<0.05$, Supplementary Table 3). Among physicians, the areas of the radar charts for the satisfaction with bDMARDs and csDMARDs were 1.72 and 1.45, respectively. In Q1, Q2, Q3, Q4, Q5, Q9, and global satisfaction (Q10), the satisfaction levels with bDMARDs were higher than those with csDMARDs for physicians $(P<0.05$, Supplementary Table 4).

\section{Factors Influencing Satisfaction}

Table 3 presents the results of the multivariable linear regressions used to determine the factors influencing patients' satisfaction with all medications. The results showed that age was positively associated with patients' satisfaction $(P=0.010)$, whereas college or above education $(P<0.001)$ and self-assessment of disease severity $(P<0.05)$ were inversely associated with patients' satisfaction. The patients' satisfaction was also positively associated with the quality of communication with the physician $(P<0.01)$ and inversely associated with treatment costs representing $31 \%-50 \%$ of the household income $(P=0.002)$. Table 4 presents the results of the multivariable linear regressions used to determine the factors influencing patients' satisfaction with bDMARDs. The results showed that college or above education $(P=0.026)$ and duration of RA $(P<0.05)$ were inversely associated, whereas self-assessment of extremely mild disease $(P=0.032)$ was positively associated with patients' satisfaction. The patients' satisfaction was also positively associated with good communication with the physician $(P=0.011)$ and inversely associated with treatment costs representing $31 \%-50 \%$ of the household income $(P=0.043)$. For physicians and patients, the long-term effectiveness was considered as the most important factor influencing long-term treatment adherence, followed by therapeutic convenience and costs (data not shown).

\section{Discussion}

Patient satisfaction influences treatment outcomes. ${ }^{8-10}$ The characteristics of RA treatment satisfaction of patients and their physicians are poorly known, especially in China. The present study reported the difference in treatment satisfaction of Chinese patients with RA and their physicians'. The results showed that the treatment satisfaction of patients with RA was generally better than that of physicians'. Among physicians, global satisfaction with bDMARDs was higher than that with csDMARDs. Age, education, disease severity, communication with the physician, and treatment costs were independently associated with the satisfaction of the patients with their treatment for RA. Age, education, and disease severity of patients are non-modifiable factors. However, physician-patient communication can be improved and should be enforced in the clinical practice. Treatment costs should be taken into account when physicians make decisions.

In the present study, patients' satisfaction (based on the TSQM-II) was relatively high. The TSQM-II provides equivalent measurements as version 1, but it uses fewer items, and the wording of the questions is more consistent. ${ }^{13}$ The TSQM-II has also been found to be equivalent to the SatMed-Q, another questionnaire for patients' satisfaction with medication. ${ }^{23}$ The TSQM has 


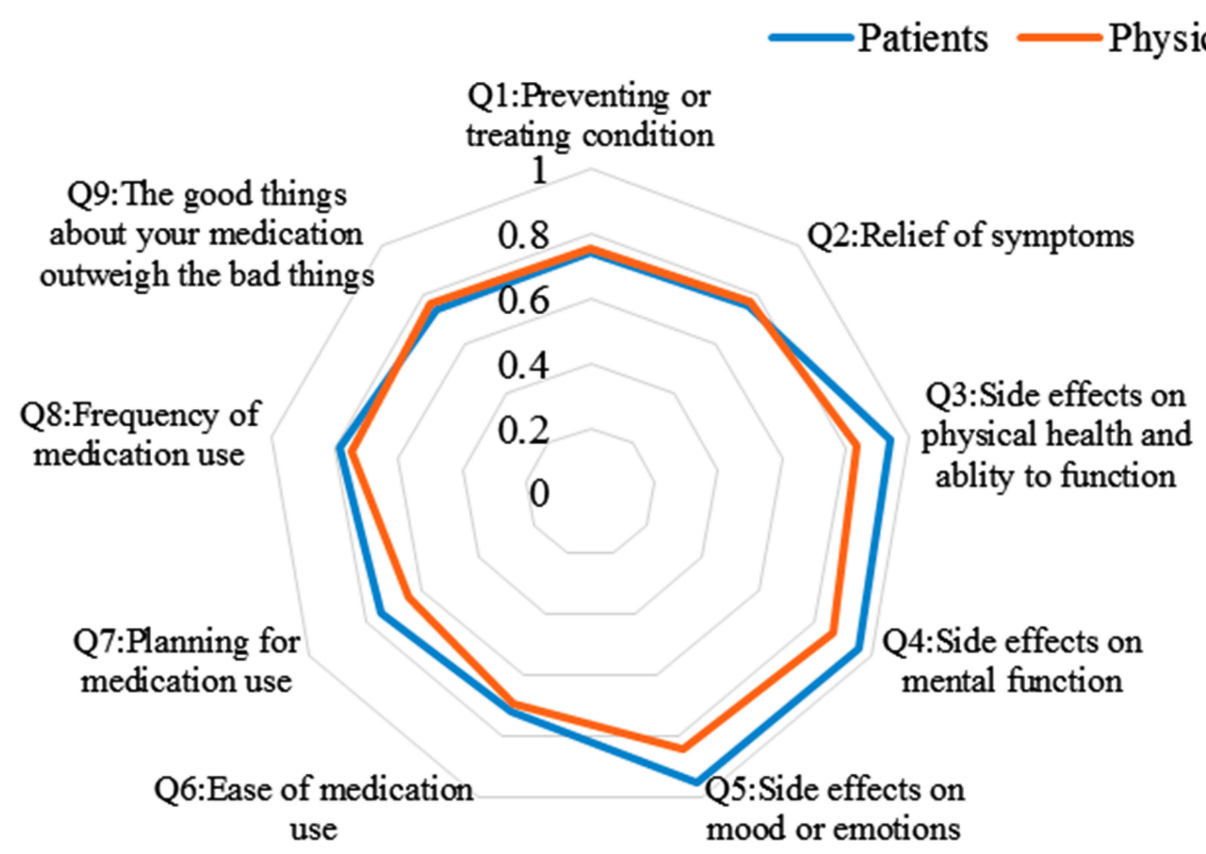

Figure 2 Radar charts with items for patients and physicians, showing satisfaction with biological disease-modifying antirheumatic drugs. P<0.05 in question (Q) 3, Q4, Q5, Q7, and Q8.

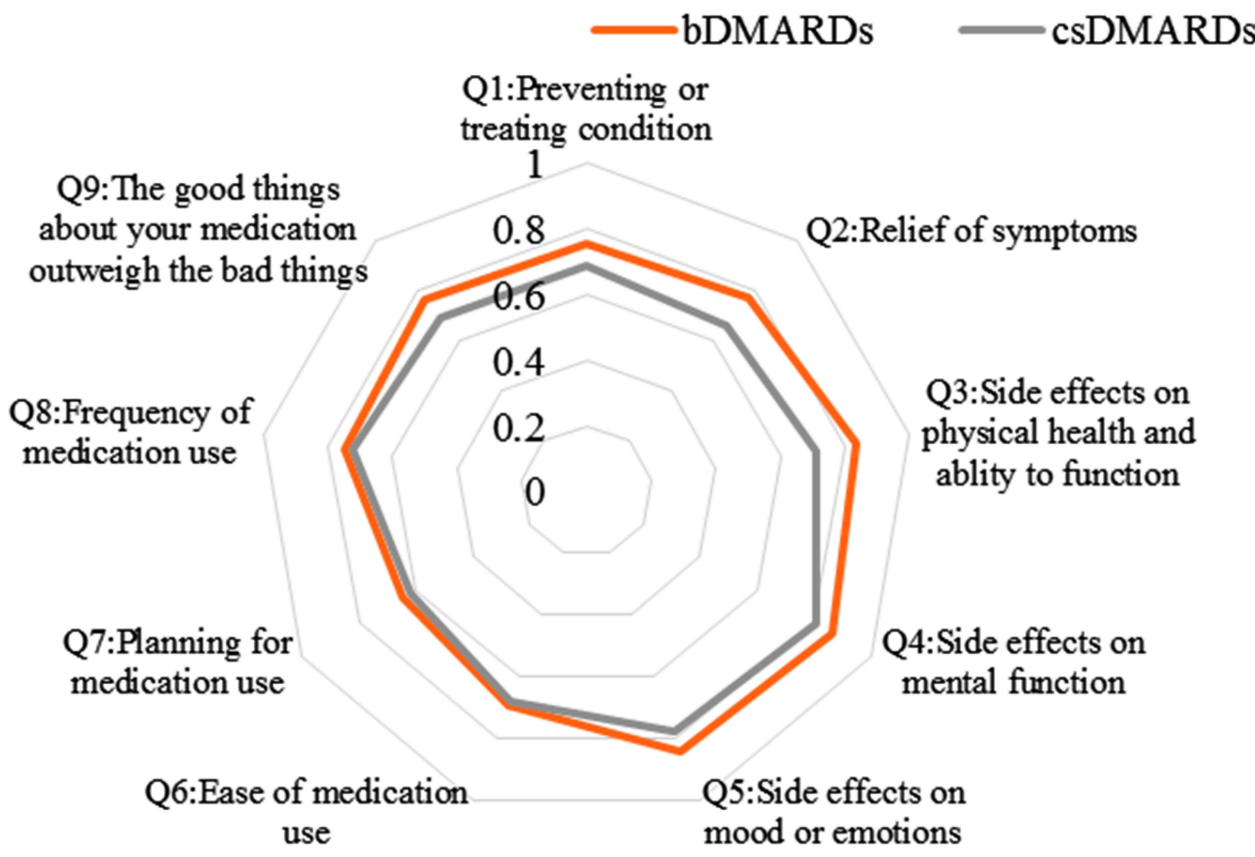

Figure 3 Radar charts with items for physicians, showing satisfaction with biological disease-modifying antirheumatic drugs (bDMARDs) and conventional synthetic DMARDs (csDMARDs). P $<0.05$ in question (Q) I, Q2, Q3, Q4, Q5, and Q9.

been shown to be reliable for chronic diseases such as multiple sclerosis, ${ }^{24}$ hypertension, ${ }^{18}$ gout, cystic fibrosis, ${ }^{25}$ and RA. ${ }^{16}$ A previous study also used TSQMII to evaluate patients' satisfaction with TNF inhibitors in patients with RA, and showed that satisfaction scores were generally in the same range as those described here. ${ }^{16}$
Other studies also reported TSQM scores that were in the same range as in this study. ${ }^{26,27}$ Nevertheless, no standard exists for evaluating patient satisfaction in general or when using the TSQM-II. A variety of methodologies were used in different studies. Using focus groups, two studies showed that the satisfaction of patients with 
Table 3 Factors Influencing the Patients' Satisfaction with All Medications, Detected Using Multivariable Linear Regression Analysis

\begin{tabular}{|c|c|c|c|c|}
\hline Factors & $\boldsymbol{\beta}$ & Se & Adjusted $\beta$ & $\boldsymbol{P}$ \\
\hline Age & 0.113 & 0.044 & 0.076 & 0.010 \\
\hline \multicolumn{5}{|l|}{ Profession } \\
\hline Office workers & Reference & & & \\
\hline Service staff & -3.515 & 2.061 & -0.058 & 0.088 \\
\hline Agricultural, forestry, animal husbandry, fisheries, and auxiliary personnel & 0.529 & 2.1 & 0.01 & 0.801 \\
\hline Manufacturing and related personnel & -4.707 & 3.286 & -0.042 & 0.152 \\
\hline Soldier and others & 1.183 & 1.596 & 0.03 & 0.459 \\
\hline \multicolumn{5}{|l|}{ Education Level } \\
\hline Junior high school and below & Reference & & & \\
\hline Senior high school & -2.709 & 1.397 & -0.061 & 0.053 \\
\hline College or above & -6.202 & 1.731 & -0.14 & $<0.001$ \\
\hline \multicolumn{5}{|l|}{ Duration of Rheumatoid Arthritis (Years) } \\
\hline$<2$ & Reference & & & \\
\hline $2-5$ & -1.937 & 1.381 & -0.044 & 0.161 \\
\hline $6-10$ & 0.703 & 1.589 & 0.014 & 0.658 \\
\hline$>10$ & -1.09 & 1.522 & -0.023 & 0.474 \\
\hline \multicolumn{5}{|l|}{ Severity of the Disease Assessed by the Patient } \\
\hline Severe & Reference & & & \\
\hline Moderate & 3.954 & 1.55 & 0.099 & 0.011 \\
\hline Mild & 8.243 & 1.664 & 0.198 & $<0.001$ \\
\hline Extremely mild & 17.201 & 3.322 & 0.152 & $<0.001$ \\
\hline \multicolumn{5}{|l|}{ Communication with Physicians } \\
\hline Full communication & Reference & & & \\
\hline Good communication, but a little hasty & -6.872 & 1.369 & -0.139 & $<0.001$ \\
\hline Average communication level and can get the information & $-12.00 \mid$ & 1.999 & -0.164 & $<0.001$ \\
\hline Less communication with physicians & -10.337 & 2.505 & -0.112 & $<0.001$ \\
\hline Basically no communication & -14.783 & 5.03 & -0.079 & 0.003 \\
\hline \multicolumn{5}{|l|}{ Cost of Treatment for Rheumatoid Arthritis, Proportion of Household Income (\%) } \\
\hline$<10$ & Reference & & & \\
\hline $10-30$ & -1.128 & 1.455 & -0.027 & 0.438 \\
\hline $31-50$ & -5.261 & 1.663 & -0.109 & 0.002 \\
\hline$>50$ & -1.931 & 1.728 & -0.04 & 0.264 \\
\hline
\end{tabular}

Raw as generally high with treatment. ${ }^{28,29}$ Many studies used homemade questionnaires, ${ }^{30-35}$ and only one of them used a rigorous method for developing the questions. ${ }^{30}$ They generally showed that the patients' satisfaction was high, but that some expectations were not always met.

In this study, the physicians' satisfaction toward bDMARDs was generally lower than that of the patients. The difference between patients and physicians was probably due to the particular concern among rheumatologists regarding the potential side effects and patients' reactions toward treatment, as supported by a previous study. ${ }^{29}$ Furthermore, some discordance between patient's global assessment and physician's global assessment was reported, ${ }^{36}$ which might also contribute to a difference in satisfaction. The discrepancies between patients' and physicians' satisfaction with bDMARDs were probably due to different opinions about the route of administration of biologics in RA, especially intravenous injection. ${ }^{37}$ The physicians' global satisfaction was higher for bDMARDs than for csDMARDs. This was probably due to the better effectiveness of bDMARDs compared with csDMARDs. Daniel et $\mathrm{al}^{27}$ showed that a shorter infusion time of golimumab was associated with higher patient and clinic staff satisfaction. Other factors could also include a belief that bDMARDs are better at treating RA, provide better symptom relief, have better side effect profile, and have 
Table 4 Factors Influencing the Patients' Satisfaction with bDMARDs, Detected Using Multivariable Linear Regression Analysis

\begin{tabular}{|c|c|c|c|c|}
\hline Factors & $\beta$ & Se & Adjusted $\beta$ & $\mathbf{P}$ \\
\hline Age & 0.037 & 0.099 & 0.021 & 0.712 \\
\hline \multicolumn{5}{|l|}{ Profession } \\
\hline Office workers & Reference & & & \\
\hline Service staff & 1.507 & 4.457 & 0.021 & 0.736 \\
\hline Agricultural, forestry, animal husbandry, fisheries, and auxiliary personnel & -0.501 & 4.843 & -0.007 & 0.918 \\
\hline Manufacturing and related personnel & -2.976 & 6.668 & -0.026 & 0.656 \\
\hline Soldier and others & 2.21 & 3.44 & 0.046 & 0.521 \\
\hline \multicolumn{5}{|l|}{ Education Level } \\
\hline Junior high school and below & Reference & & & \\
\hline Senior high school & -4.69 & 3.352 & -0.092 & 0.163 \\
\hline College or above & -8.397 & 3.742 & -0.175 & 0.026 \\
\hline \multicolumn{5}{|l|}{ Duration of Rheumatoid Arthritis (Years) } \\
\hline$<2$ & Reference & & & \\
\hline $2-5$ & -10.675 & 3.567 & -0.207 & 0.003 \\
\hline $6-10$ & -7.456 & 3.772 & -0.135 & 0.049 \\
\hline$>10$ & -15.578 & 3.753 & -0.29 & $<0.001$ \\
\hline \multicolumn{5}{|l|}{ Severity of the Disease Assessed by the Patient } \\
\hline Severe & Reference & & & \\
\hline Moderate & 3.15 & 3.466 & 0.068 & 0.364 \\
\hline Mild & 2.369 & 3.957 & 0.045 & 0.550 \\
\hline Extremely mild & 16.634 & 7.736 & 0.122 & 0.032 \\
\hline \multicolumn{5}{|l|}{ Communication with Physicians } \\
\hline Full communication & Reference & & & \\
\hline Good communication, but a little hasty & -7.79 & 3.036 & -0.144 & 0.011 \\
\hline Average communication level and can get the information & -8.008 & 4.534 & -0.095 & 0.078 \\
\hline Less communication with physicians & -5.296 & 5.302 & -0.054 & 0.319 \\
\hline Basically no communication & -7.553 & $13.15 \mid$ & -0.031 & 0.566 \\
\hline \multicolumn{5}{|l|}{ Cost of Treatment for Rheumatoid Arthritis, Proportion of Household Income (\%) } \\
\hline$<10$ & Reference & & & \\
\hline $10-30$ & -5.222 & 4.259 & -0.107 & 0.221 \\
\hline $31-50$ & -9.376 & 4.622 & -0.167 & 0.043 \\
\hline$>50$ & -8.731 & 4.510 & -0.174 & 0.054 \\
\hline
\end{tabular}

Abbreviations: RA, rheumatoid arthritis; bDMARDs, biological disease-modifying antirheumatic drugs; TSQM-II, Treatment Satisfaction Questionnaire for Medication, version II; CREDIT, Chinese Registry of Rheumatoid Arthritis; EULAR, European League Against Rheumatism; ACR, American College of Rheumatology; DAS28, Disease Activity Score 28; SD, standard deviation; csDMARDS, conventional synthetic disease-modifying antirheumatic drugs; DAS28-ESR, disease activity score 28-erythrocyte sedimentation rate; DAS28-CRP, disease activity score 28-C-reactive protein; PtGA, patient global assessment of disease activity; bDMARDs, biological disease-modifying antirheumatic drugs.

less effect on mental function and mood, as supported by previous studies. ${ }^{38-41}$

The multivariable analysis showed that education level, self-assessment of disease severity, bad communication with physicians, and treatment costs were negatively associated with the treatment satisfaction of the patients with all medications. Education level, duration of RA, and treatment costs were negatively associated with the treatment satisfaction of the patients with bDMARDs. Patients with a high level of self-assessment of disease severity might suffer more, leading to low satisfaction, as generally observed in various diseases, including RA. ${ }^{42-45}$ In addition, there was no correlation between DAS-28 and treatment satisfaction. DAS-28 represents the current level of disease activity, which is different from the severity throughout the course of the disease. The patient's assessment of disease severity was more subjective, reflecting the severity and their global experience throughout the whole course of the disease. The multivariable analysis also showed that appropriate communication between the patients and their physicians could improve 
patients' satisfaction, as supported by a previous study. ${ }^{46}$ The overarching principles of the 2014 treat-to-target recommendations requested that the treatment of rheumatoid arthritis must be based on a shared decision between patient and rheumatologist. ${ }^{47}$ Furthermore, shared decision-making could affect the treatment choices for rheumatic diseases and patient satisfaction. ${ }^{48}$ Better communication can improve mutual trust and rational decision-making between patients and rheumatologists. ${ }^{49}$ A recent study showed that the physicians should properly address the patients' concerns with treatment in order to improve their adherence and that the expectations with treatment should be clearly delineated from the start. ${ }^{50}$ Interestingly, self-assessment of disease severity and communication with physicians were not associated with the treatment satisfaction of patients with bDMARDs. The favorable effectiveness of bDMARDs satisfied patients regardless of disease severity and communication. In addition, patients with shorter duration of RA were more satisfied with bDMARDs, indicating the benefit of early treatment with bDMARDs. High treatment costs were also an important factor independently affecting patients' satisfaction with all medications or bDMARDs. The Chinese New Cooperative Medical Scheme Coverage provides financial protection for households with chronic diseases, but it is believed that reimbursement policies need to be strengthened in the future in order to improve patients' satisfaction, quality of life, and treatment adherence. ${ }^{51}$ In addition to costs, this study found that the long-term effectiveness and treatment convenience were the two most important factors affecting long-term treatment adherence and persistence in RA for both patients and physicians. In addition, a significant correlation was found when the cost of RA treatment was $31-50 \%$ of the total household income, but not for that of $>50 \%$. The most probable explanation is that among patients who spent $>50 \%$ of their income on RA drugs, many of them were using higher-priced bDMARDs. Better treatment effectiveness of bDMARDs has been shown compared with csDMARDs in previous studies. ${ }^{38-41}$ The improved treatment effect with bDMARD in patients who spent $>50 \%$ of their income on RA drugs might counteract the negative effect of a higher financial burden on patient satisfaction.

This study has limitations. This was an observational study with only 12 representative centers from 11 provinces in China. Of course, the generalizability of the results could be limited since it was not a nationwide study and that disparities may exist among provinces. In addition, there might be some potential selection bias because only the participants of CREDIT registry were invited. Multivariable linear regression was performed to reduce the bias and influence from the confounding factors, but some residual bias is possible. For questionnaire simplicity and feasibility, this study did not include questions on patients' satisfaction with csDMARDs, neither patients' nor rheumatologists' satisfaction with steroids and non-steroidal anti-inflammatory drugs (NSAIDs). Future studies should explore the complete treatment patterns of RA in a more comprehensive manner. Moreover, reliable patient-reported outcome indicators such as health assessment questionnaire scores were not included in this study. Those indicators could provide more depth into the understanding of the factors affecting patients' and physicians' satisfaction with RA treatments. We will explore these indicators in the future. The use of modern technologies, such as mobile apps, could also improve patients' satisfaction $^{52}$ and should be explored. Non-uniform scoring methods and calculations for different items and domains of the TSQM-II questionnaire might influence the reliability of results. Finally, the reliability and validity of the Chinese version of TSQM-II were not assessed.

\section{Conclusion}

In conclusion, the treatment satisfaction of Chinese patients with RA is generally higher than that of the physicians involved in the management of patients with RA. Physicians are more satisfied with bDMARDs than csDMARDs. The multivariable analysis showed that age, education, disease severity, communication with physicians, and treatment costs are independently associated with patients' satisfaction. The results provide evidence for improving patient satisfaction and shared decision management in Chinese patients with RA. Age, education, and disease severity of patients are nonmodifiable factors. However, physician-patient communication can be improved and should be enforced in the clinical practice. Treatment costs should be taken into account when physicians make decisions.

\section{Acknowledgments}

The authors acknowledge contributions from the HealthCloud Co., Ltd as the system provider.

\section{Data Sharing}

Deidentified participant data and protocol are available upon reasonable request to the Corresponding Author. Data can be available for a period of 10 years. 


\section{Funding}

This study was supported by the Chinese National Key Technology R\&D Program (2017YFC0907601, 2017YFC0907604).

\section{Disclosure}

The authors report no conflicts of interest in this work.

\section{References}

1. Klarenbeek NB, Kerstens PJ, Huizinga TW, Dijkmans BA, Allaart CF. Recent advances in the management of rheumatoid arthritis. BMJ. 2010;341(dec21 1):c6942. doi:10.1136/bmj.c6942

2. Deighton C, O'Mahony R, Tosh J, Turner C, Rudolf M. Guideline Development G. Management of rheumatoid arthritis: summary of NICE guidance. BMJ. 2009;338(mar16 1):b702. doi:10.1136/bmj. b702

3. Rindfleisch JA, Muller D. Diagnosis and management of rheumatoid arthritis. Am Fam Physician. 2005;72(6):1037-1047.

4. Smolen JS, Landewe R, Bijlsma J, et al. EULAR recommendations for the management of rheumatoid arthritis with synthetic and biological disease-modifying antirheumatic drugs: 2016 update. Ann Rheum Dis. 2017;76(6):960-977. doi:10.1136/annrheumdis-2016210715

5. Smolen JS, Aletaha D, Barton A, et al. Rheumatoid arthritis. Nat Rev Dis Prim. 2018;4(1):18001. doi:10.1038/nrdp.2018.1

6. Baker JF, Sauer B, Teng -C-C, et al. Initiation of disease-modifying therapies in rheumatoid arthritis is associated with changes in blood pressure. J Clin Rheumatol. 2018;24(4):203-209. doi:10.1097/ RHU.0000000000000736

7. Wilsdon TD, Hill CL. Managing the drug treatment of rheumatoid arthritis. Aust Prescr. 2017;40(2):51-58. doi:10.18773/austprescr. 2017.012

8. Bowling A, Ebrahim S. Measuring patients' preferences for treatment and perceptions of risk. Qual Health Care. 2001;10(Supp1 1):i2-8. doi:10.1136/qhc.0100002

9. Barton JL. Patient preferences and satisfaction in the treatment of rheumatoid arthritis with biologic therapy. Patient Prefer Adherence. 2009;3:335-344. doi:10.2147/PPA

10. Louder AM, Singh A, Saverno K, et al. Patient preferences regarding rheumatoid arthritis therapies: a conjoint analysis. Am Health Drug Benefits. 2016;9:84-93.

11. Marengo MF, Suarez-Almazor ME. Improving treatment adherence in patients with rheumatoid arthritis: what are the options? Int J Clin Rheumatol. 2015;10(5):345-356. doi:10.2217/ijr.15.39

12. Gadallah MA, Boulos DN, Gebrel A, Dewedar S, Morisky DE. Assessment of rheumatoid arthritis patients' adherence to treatment. Am J Med Sci. 2015;349(2):151-156. doi:10.1097/MAJ.0000000 000000376

13. Atkinson MJ, Kumar R, Cappelleri JC, Hass SL. Hierarchical construct validity of the treatment satisfaction questionnaire for medication (TSQM version II) among outpatient pharmacy consumers. Value Health. 2005;8(Suppl 1):S9-S24. doi:10.1111/j.1524-4733. 2005.00066.x

14. Atkinson MJ, Sinha A, Hass SL, et al. Validation of a general measure of treatment satisfaction, the Treatment Satisfaction Questionnaire for Medication (TSQM), using a national panel study of chronic disease. Health Qual Life Outcomes. 2004;2(1):12. doi:10. $1186 / 1477-7525-2-12$

15. Khanna PP, Shiozawa A, Walker V, et al. Health-related quality of life and treatment satisfaction in patients with gout: results from a cross-sectional study in a managed care setting. Patient Prefer Adherence. 2015;9:971-981. doi:10.2147/PPA.S83700
16. Jobanputra P, Maggs F, Deeming A, et al. A randomised efficacy and discontinuation study of etanercept versus adalimumab (RED SEA) for rheumatoid arthritis: a pragmatic, unblinded, non-inferiority study of first TNF inhibitor use: outcomes over 2 years. BMJ Open. 2012;2.

17. Lin Q, Lin Z, Gu J, et al. Abnormal high-expression of CD154 on $\mathrm{T}$ lymphocytes of ankylosing spondylitis patients is down-regulated by etanercept treatment. Rheumatol Int. 2010;30(3):317-323. doi:10.1007/s00296-009-0958-8

18. Bharmal M, Payne K, Atkinson MJ, Desrosiers MP, Morisky DE, Gemmen E. Validation of an abbreviated Treatment Satisfaction Questionnaire for Medication (TSQM-9) among patients on antihypertensive medications. Health Qual Life Outcomes. 2009;7:36. doi:10.1186/1477-7525-7-36

19. Yu C, Li M, Duan X, et al. Chinese registry of rheumatoid arthritis (CREDIT): I. Introduction and prevalence of remission in Chinese patients with rheumatoid arthritis. Clin Exp Rheumatol. 2018; 36:836-840.

20. Jin S, Li M, Fang Y, et al. Chinese Registry of rheumatoid arthritis (CREDIT): II. prevalence and risk factors of major comorbidities in Chinese patients with rheumatoid arthritis. Arthritis Res Ther. 2017; 19:251.

21. Aletaha D, Neogi T, Silman AJ, et al. 2010 rheumatoid arthritis classification criteria: an American College of Rheumatology/ European League Against Rheumatism collaborative initiative. Arthritis Rheum. 2010;62(9):2569-2581. doi:10.1002/art.27584

22. Yin R, Cao H, Fu T, et al. The rate of adherence to urate-lowering therapy and associated factors in Chinese gout patients: a cross-sectional study. Rheumatol Int. 2017;37:1187-1194. doi:10.10 07/s00296-017-3746-x

23. Delestras S, Roustit M, Bedouch P, et al. Comparison between two generic questionnaires to assess satisfaction with medication in chronic diseases. PLoS One. 2013;8:e56247. doi:10.1371/journal. pone. 0056247

24. Vermersch P, Hobart J, Dive-Pouletty C, Bozzi S, Hass S, Coyle PK. Measuring treatment satisfaction in MS: is the Treatment Satisfaction Questionnaire for Medication fit for purpose? Multiple Sclerosis. 2017;23(4):604-613. doi:10.1177/1352458516657441

25. Regnault A, Balp -M-M, Kulich K, Viala-Danten M. Validation of the Treatment Satisfaction Questionnaire for Medication in patients with cystic fibrosis. J Cystic Fibrosis. 2012;11(6):494-501. doi:10.1016/j. jef.2012.04.007

26. Van den Bosch F, Ostor AJK, Wassenberg S, et al. Impact of participation in the adalimumab (Humira) patient support program on rheumatoid arthritis treatment course: results from the PASSION study. Rheumatol Ther. 2017;4(1):85-96. doi:10.1007/s40744-0170061-7

27. Daniel SR, McDermott JD Jr, Le C, Pierce CA, Ziskind MA, Ellis LA. A real-world, multi-site, observational study of infusion time and treatment satisfaction with rheumatoid arthritis patients treated with intravenous golimumab or infliximab. $J$ Med Econ. $2018 ; 1-8$.

28. Marshall NJ. Patients' perceptions of treatment with anti-TNF therapy for rheumatoid arthritis: a qualitative study. Rheumatology. 2004;43(8):1034-1038. doi:10.1093/rheumatology/keh237

29. van Tuyl LH, Plass AM, Lems WF, et al. Discordant perspectives of rheumatologists and patients on COBRA combination therapy in rheumatoid arthritis. Rheumatology. 2008;47(10):1571-1576. doi:10. 1093/rheumatology/ken323

30. Carbonell J, Badia X, grupo E. Expectations, preferences and satisfaction of patients with rheumatoid arthritis receiving infliximab treatment. Med Clin (Barc). 2008;131:493-499.

31. Kjeken I, Dagfinrud H, Mowinckel P, Uhlig T, Kvien TK, Finset A. Rheumatology care: involvement in medical decisions, received information, satisfaction with care, and unmet health care needs in patients with rheumatoid arthritis and ankylosing spondylitis. Arthritis Rheum. 2006;55:394-401. doi:10.1002/art.21985 
32. Rao JK, Weinberger M, Anderson LA, Kroenke K. Predicting reports of unmet expectations among rheumatology patients. Arthritis Rheum. 2004;51(2):215-221. doi:10.1002/art.20246

33. Wolfe F, Michaud K. Resistance of rheumatoid arthritis patients to changing therapy: discordance between disease activity and patients' treatment choices. Arthritis Rheum. 2007;56:2135-2142. doi:10.10 02/art.22719

34. Henao S, Rodriguez F, Santos-Moreno P, et al. patient satisfaction in a rheumatoid arthritis specialized center. Ann Rheum Dis. 2016;76: AB1207-HPR

35. Calvo-Alen J, Vela P, Bustabad S, Maceiras F, Carmona L, Cea-Calvo L. Satisfaction, fulfillment of expectations and adherence to subcutaneous biological drugs in patients with rheumatoid arthritis: ARCO study. Rheumatol Clin. 2018. doi:10.1016/j.reuma.2018.04.002

36. Ward MM, Guthrie LC, Alba MI. Standards of comparison and discordance in rheumatoid arthritis global assessments between patients and clinicians. Arthritis Care Res (Hoboken). 2017;69:12 60-1265. doi:10.1002/acr.23103

37. De Mits S, Lenaerts J, Vander Cruyssen B, et al. A nationwide survey on patient's versus physician $\mathrm{s}$ evaluation of biological therapy in rheumatoid arthritis in relation to disease activity and route of administration: the be-raise study. PLoS One. 2016;11(11):e0166607. doi:10.1371/journal.pone.0166607

38. Rein P, Mueller RB. Treatment with biologicals in rheumatoid arthritis: an overview. Rheumatol Ther. 2017;4(2):247-261. doi:10.1007/ s40744-017-0073-3

39. Choy E, Aletaha D, Behrens F, et al. Monotherapy with biologic disease-modifying anti-rheumatic drugs in rheumatoid arthritis Rheumatology. 2017;56(5):689-697. doi:10.1093/rheumatology/kew271

40. Bechman K, Sin FE, Ibrahim F, et al. Mental health, fatigue and function are associated with increased risk of disease flare following TNF inhibitor tapering in patients with rheumatoid arthritis: an exploratory analysis of data from the Optimizing TNF Tapering in RA (OPTTIRA) trial. RMD Open. 2018;4(1):e000676. doi:10.1136/ rmdopen-2018-000676

41. Matcham F, Galloway J, Hotopf M, et al. The impact of targeted rheumatoid arthritis pharmacologic treatment on mental health: a systematic review and network meta-analysis. Arthritis Rheumatol. 2018;70(9):1377-1391. doi:10.1002/art.40565
42. Asadi-Lari M, Tamburini M, Gray D. Patients' needs, satisfaction, and health related quality of life: towards a comprehensive model. Health Qual Life Outcomes. 2004;2(1):32. doi:10.1186/1477-7525-2-32

43. Basinska MA, Drozdowska M. Emotional intelligence as an indicator of satisfaction with life of patients with psoriasis. Postepy Dermatol Alergol. 2013;30:365-372. doi:10.5114/pdia.2013.39435

44. Barton JL, Imboden J, Graf J, Glidden D, Yelin EH, Schillinger D. Patient-physician discordance in assessments of global disease severity in rheumatoid arthritis. Arthritis Care Res (Hoboken). 2010;62 (6):857-864. doi:10.1002/acr.20132

45. Walker UA, Mueller RB, Jaeger VK, et al. Disease activity dynamics in rheumatoid arthritis: patients' self-assessment of disease activity via WebApp. Rheumatology (Oxford). 2017;56(10):1707-1712. doi:10.1093/rheumatology/kex229

46. Aoki A, Suda A, Takeno M, Ishigatsubo Y, Maeda I. Determinants of factors influencing patient satisfaction in rheumatoid arthritis. Clin Rheumatol Rel Res. 2010;22:42-50.

47. Smolen JS, Breedveld FC, Burmester GR, et al. Treating rheumatoid arthritis to target: 2014 update of the recommendations of an international task force. Ann Rheum Dis. 2016;75(1):3-15. doi:10.1136/ annrheumdis-2015-207524

48. Lofland JH, Johnson PT, Ingham MP, Rosemas SC, White JC, Ellis L. Shared decision-making for biologic treatment of autoimmune disease: influence on adherence, persistence, satisfaction, and health care costs. Patient Prefer Adherence. 2017;11:947-958. doi:10.2147/PPA.S133222

49. Feinberg J. The effect of patient-practitioner interaction on compliance: a review of the literature and application in rheumatoid arthritis. Patient Educ Couns. 1988;11(3):171-187. doi:10.1016/073 8-3991(88)90018-3

50. Cea-Calvo L, Raya E, Marras C, et al. The beliefs of rheumatoid arthritis patients in their subcutaneous biological drug: strengths and areas of concern. Rheumatol Int. 2018.

51. Jing S, Yin A, Shi L, Liu J. Whether new cooperative medical schemes reduce the economic burden of chronic disease in rural China. PLoS One. 2013;8:e53062. doi:10.1371/journal.pone.0053062

52. Wang P, Luo D, Lu F, et al. A novel mobile app and population management system to manage rheumatoid arthritis flares: protocol for a randomized controlled trial. JMIR Res Protoc. 2018;7(4):e84. doi:10.2196/resprot.8771
Patient Preference and Adherence

\section{Publish your work in this journal}

Patient Preference and Adherence is an international, peer-reviewed, open access journal that focuses on the growing importance of patient preference and adherence throughout the therapeutic continuum. Patient satisfaction, acceptability, quality of life, compliance, persistence and their role in developing new therapeutic modalities and compounds to optimize clinical outcomes for existing disease states are major areas of interest for the journal. This journal has been accepted for indexing on PubMed Central. The manuscript management system is completely online and includes a very quick and fair peer-review system, which is all easy to use. Visit http:// www.dovepress.com/testimonials.php to read real quotes from published authors. 